J. Product. \& Dev., 14(2): 375 - 390 (2009)

\title{
EFFECT OF SOME POSTHARVEST TREATMENTS ON PEPPERMENT QUALITY
}

\section{H.R.A. Mehasen; A.M.A Hamouda and S.G.I.Soliman}

MAPs Department, Horticulture Research Institute, Agricultural Research Center, Giza, Egypt.

\begin{abstract}
The present investigation was conducted in season (20062007) to study the best harvesting method, the best drying method, packages type and storage period in peppermint which give the lowest average of total microbial count (TMC) and best essential oil content with active ingredients of the oil. The results of this study indicated that the best harvesting method occurred with using gloves with clear plastic, harvesting boxes; while, the best drying system was the solar drying. The best package type through storage period was carton boxes; increasing storage period decreased the volatile oil percentage and the most of main components.
\end{abstract}

Key words: Postharvest, pepperment quality.

\section{INTRODUCTION}

Production and exportation of Herbs, Medicinal and Aromatic Plants (HMAPs) faces many constraints i.e., high level of pesticides residues, shortage of applying GAP which led to high microbial load and use of old techniques in postharvest and processing (Shalaby et al,1988).

Peppermint (Mentha $\times$ piperita) Fam. Lamiaceae (Labiatae) is a hybrid mint, a cross between watermint (Mentha aquatica) and spearmint (Mentha spicata). The plant is indigenous in Europe and now widespread in cultivation throughout all regions of the world. It is found wild occasionally with its parent species (Ozguven and Kirici, 1999). Peppermint has a high menthol content, and is often used as a flavoring in tea, ice cream, confectionery, chewing gum, and toothpaste. The oil also contains menthone and menthyl esters. It is the oldest and most popular flavor of mint-flavored confectionery (Oyedeji and Afolayan, 2005).

Postharvest processes are very important in the production of HMAPs since they affect significantly the quantity and quality of these crops. Post harvest 
starts from the time of harvest or collection. The time at which each crop is collected is usually of considerable importance. Postharvest technology includes drying, grinding, packaging, storage and essential oil extraction.

Drying constitutes the most important processing step in postharvest technology. The main object of drying is to reduce moisture content present at harvest time to a safe limit (8-12 \%) (Muller et al, 1996). At this moisture level, the chances of insect and mold infestation are minimized, and thus the commodity can be kept well (Mohamed, 2005 and Fatouh et al, 2006).

Since HMAPs contain volatile aromatic principals, the loss of these volatiles and absorption of foreign odors as a result of inefficient packaging may pose serious problems. HMAPs can be packaged in bags designed to minimize water loss. When HMAPs are packaged by this way, it is particularly important to maintain constancy of fungal or bacterial growth. The bags may be partially permeable to water vapor. The relative humidity in the packaging area, cold rooms, and transport vehicles should be maintained at a high level (>95\%) where particle ( AI-Kershi, 2003).

Storage is an important stage for successful marketing. In the absence of proper storage conditions, HMAPs not only lose their characteristic aroma, color and flavor (Stafford et al, 2004), they also pick up moisture, become moldy and unattractive, then spoilage sets in. (Mimica et al, 2003). In this way the type of storage packages is an important factor which affects of HMAPs marketing (Tomkins and Chennell, 2000).

\section{MATERIALS AND METHODS}

Field experiment was conducted in Fayoum during (2006-2007) on a 0.25 faddan in an organically certified Farm managed by Omar Ibn Alkhattab Association to study harvesting practices, handling, drying methods, packaging and storage period on peppermint quality. The treatments were as follows:-

\section{1: Harvesting and handling treatments:}

- Three harvesting treatments were used as follows:-

1- The traditional harvesting in which the herb was collected by bare hands (T1).

2-The herb using sterile hand and tools dipped in Dettol (5\% for 10 seconds) (T2).

3- The laborers wore gloves and protection gears for head and feet (T3).

-Three handling treatments were used as follows:- 
(1) Traditional method: The harvested herb was put directly on the ground (C1- control).

(2) The harvested herb was put directly on plastic sheet (C2).

(3) The harvested herb was put directly in clear plastic containers (C3).

\section{2- Drying methods:-}

- Three drying methods were used as follows:-:

1- Natural drying involves placing the herb on craft paper in the sun for 24 hours then transferring it into the shade (D1).

2- The second method involves drying peppermint in direct sun (D2).

3- The third method is Solar drying involves using a tunnel solar drying facility (D3).

\section{3-Packaging process:-}

Three packaging types (plastic cases, Jute cases and carton boxes) were used for each drying method. The samples of dried peppermint herb were packed and stored for one year (from September 2006 till Sep 2007) in standard storage room in the same farm where the temperature was $(25 \pm 1)$ and the relative humidity ranged was from 25 to $40 \%$.

Each treatment included three replicates and each replicate was 5 kilogram of peppermint dry herb. The stored samples of the dry herb in the different packages were studied for the tested characters in zero time of storage in Sep 2006 and every four months (Jan, May and Sep 2008).

\section{Data recorded}

- Total Microbes Count (TMC) per gram sample of all treatments was determined using nutrient agar medium according to the procedure described by (Merck, 1977).

- Volatile oil percentage and volatile oil content of fresh and dry herb for each sample were determined using the method described in British pharmacopoeia (1963).

- GLC analysis as outlined by Harris (2003). For the chemical composition of peppermint essential oil of each treatment, was carried out at the central herb of chemical analysis-National Research Center.

\section{- Statistical analysis}

The experiment was designed in Complete Randomized System and was statistically analyzed by Costat analysis program using LSD at 5\% level according to Snedecor and Cochran (1967).

\section{RESULTS AND DISCUSSION}




\section{Effect of harvesting and handling methods on TMC:}

Data presented in Table (1) showed significant decrease in TMC in response to harvesting methods, handling and the interaction between them in comparison with the traditional harvesting and handling methods.

Similarly, harvesting with sterile gloves treatment followed by sterilizing labor hands and tools with dettol gave the lowest average of TMC (1.05 and 1.54 million/ g., respectively). However, the traditional method of harvesting (by hands) gave the highest average of TMC (7.27 million/ g.) which may due to infestation by microbes through labor hands to the harvested herb.

The results also showed that the lowest average of TMC occurred with plants harvested and put in clear plastic box and clear plastic sheet (1.03 and 1.5 million/ g., respectively). On the other hand, the plants which were harvested and put on the ground recorded the largest average of TMC (7.27 million/g). This may due to the microbial spoilage from the soil to the harvested herb. The lowest average of TMC ( 0.74 million/ g.) was occurred when peppermint plants were harvested using gloves then the herb was handled in clear plastic boxes (T3 X C3). The same result was found in case of T2X C2 treatment, the TMC showed insignificant differences comparing with T3 C3 treatment. Data also indicated that the traditional method of harvesting and handling ( $\mathrm{T} 1$ and $\mathrm{C} 1$ ) gave the highest average of TMC (7.1 million/g.).

It could be concluded that, using gloves, sterilized tools and keeping the herb in plastic sheets or clear plastic boxes minimized TMC in the harvested herb. These results were in agreement with Zheljazkov et al (1999).

Table 1. Effect of harvesting and handling methods on TMC (million/ g.).

\begin{tabular}{|c|c|c|c|c|}
\hline \multirow{3}{*}{$\begin{array}{l}\text { Handling treatments } \\
\text { (C) }\end{array}$} & \multicolumn{4}{|c|}{ Harvesting methods (T) } \\
\hline & $\begin{array}{l}\text { Traditional } \\
\text { (1) }\end{array}$ & $\begin{array}{l}\text { With sterile } \\
\text { solution } \\
(2)\end{array}$ & $\begin{array}{l}\text { With } \\
\text { gloves } \\
\text { (3) }\end{array}$ & Mean \\
\hline & \multicolumn{4}{|c|}{ Total Microbes Count (TMC) million/g. } \\
\hline Ground (traditional) (1) & 7.27 & 2.33 & 1.43 & 3.67 \\
\hline Plastic sheet & 2.35 & 1.17 & 1.0 & 1.50 \\
\hline Clear plastic box (3) & 1.25 & 1.12 & 0.74 & $\mathbf{1 . 0 3}$ \\
\hline Mean & 3.62 & 1.54 & 1.05 & \\
\hline L.S.D. at $5 \%$ & & & & 0.17 \\
\hline $\mathbf{C}$ & & & & 0.17 \\
\hline $\mathbf{T} \times \mathbf{C}$ & & & & 0.30 \\
\hline
\end{tabular}

T: Harvesting treatments

C: Handling methods 
2. Effect of drying methods, storage packaging and storage period on TMC (million/ g.), volatile oil content and oil components of peppermint:

a-TMC average (million/g.)

Data presented in Table 2, showed significant decrease in TMC average in dry herb using solar drying followed by shade and finally drying in the direct sun $(1.50,5.57$ and 7.1 million/ g, respectively), the type of storage packaging and the interaction between them through the storage period.

The lowest average of TMC (1.09 million/ g.)stored for 4 months was occurred when using solar drying however, direct sun and shad drying method gave the highest TMC average 8.82 and 9.70 million/g, respectively.

TMC average in peppermint herb recorded the lowest values throughout one year storage period in case of drying using solar drying system in comparison with the other drying methods. The TMC values were 1.50, 1.09, 1.32 and 1.69 million/g., in Sep 2006, Jan, May and Sep 2007.

Using carton boxes or plastic cases proved the best materials for storage dry herb for long periods with less TMC. This can be explained on the basis of studies of suggestions of AI-Kershi (2003).

Accordingly, data in Table (2) obviously emphasized that, the interaction between the drying method and the packages types resulted in a significant decrease in TMC in dry peppermint herb.

It was found that, lowest average of TMC in peppermint dry herb was recorded in case of solar drying method and storing the dried herb in carton boxes or plastic cases during the storage period. Values were found to be statistically the same for plastic cases and carton boxes and were $0.88-.091,0.99$ - 1.18 and $1.22-1.38$ million/ g., in Jan, May and Sep 2007, respectively. These results were in agreement with Manuel et al. (2008).

\section{2. b.-Volatile oil percentage and the active ingredients: b-1- Volatile oil percentage:}

Data presented in Table 3 showed significant differences in volatile oil percentage through the zero time storage, after four months, after herb storage for eight months and one year storage which due to the effect of storage treatments.

Data also indicated that, volatile oil of peppermint herb was found to be affected by drying methods. The highest volatile oil content was recorded in case of solar drying method (1.52\%), while the lowest one was found in direct sun drying $(1.43 \%)$. The differences between the values of volatile oil content of the three drying methods were significant. 
It could be concluded that, the best drying method was solar drying system in which the evaporation of volatile oil of the peppermint herb was less than the other drying methods. As for the storage period, data also indicated by storage period. It was found that, volatile oil content gradually decreased as the storage period was increased.

So, peppermint volatile oil percentage was (1.47\% average) in zero time (Sep. 2006) then this value was decreased to $1.32 \%$ after four months, $1.21 \%$ after eight months and the lowest decrement $(1.06 \%)$ was recorded after one year storage, regardless the storage packages.

Concerning the packaging types and its effect on volatile oil percentage of peppermint dried herb, it was pointed out that, the packaging type was found to be either preserved the volatile oil percentage of peppermint dried herb, or led to a sharp decrement, this trend was clearly showed throughout the storage period. Accordingly, the highest volatile oil percentage was detected in case of carton boxes, while the lowest one found in plastic cases. Data also emphasized that, an interaction was found between the three factors that used in this study. It was found that, after one year storage period the highest volatile oil percentage was determined in peppermint herb with using solar drying method and packaging in carton boxes the value in this respect was $1.32 \%$. On the contrary, lowest value of peppermint oil percentage was obtained after one year storage with using plastic cases and Jute cases regardless the drying method.

On the light of these findings, it could be concluded that the best quality of peppermint herb (in view of oil percentage) was obtained by using solar drying method for dried herb in carton boxes for a period prolonged to one year. In this case the volatile oil percentage was $1.06 \%$ comparing to $1.47 \%$ at the zero time (Sep 2006). The reduction in volatile oil percentage was estimated by $13.16 \%$ after one year storage.

In addition, the results showed that the best drying system, which gave the highest percentage in peppermint oil, solar drying system. In addition, the storage package, which gave the highest percentage volatile oil, was carton. Similarly, the highest percentage of peppermint volatile oil after one year storage $(1.32 \%)$ occurred with using solar drying system with carton boxes (D1or D3+ carton).

In general, the data reported that the volatile oil percentage of peppermint from the dried herb with the three dry methods was decreased through the storage period from zero time to one year storage. Also, the best storage packaging was the carton which gave the lowest decreasing level in the oil percentage. These results may due to those postharvest treatments may be affect the chemical composition and biological activity of medicinal plant 
material. These include the common practices of drying and re-dissolving plant extracts; various filtering methods; the application of heat and; the use of liquid nitrogen to grind plant material. Information, such as storage period and conditions, therefore, should be noted and included in published results. Since accelerated ageing (Stafford et al, 2004 and Asekun et al, 2007) allows plant material to be rapidly aged, studying the effects of storage on plant material is less time consuming. This is especially relevant to medicinal plant materials traded in traditional African markets, most of which are exposed to high temperatures and/ or humidity levels, such as those experienced in coastal regions like Durban which has one of South Africa's largest markets.

\section{b-2-Menthol percentage}

The data in Table 4 indicated that the solar drying method in solar drying system gave the highest percentage of menthol in Peppermint oil followed by the shade drying and direct sun drying (55.2, 51.33 and 50.1\%, respectively).

Data presented in Table 4 showed that, menthol value of peppermint oil was found to be affected by drying methods. The highest menthol percentage was recorded in case of solar drying method $(55.2 \%)$, while the lowest one was found in direct sun drying $(50.1 \%)$. The differences between the values of menthol percentage of the three drying methods were significant.

So it could be reported that, the best drying method was solar drying system in which the evaporation of volatile oil of the peppermint herb was less than the other drying methods. As for the storage period, data also indicated by storage period. It was found that, menthol percentage gradually decreased as the storage period was increased. So, menthol percentage was (52.1\% average) in Zero time (sep.2006) then this value was decreased to $46.3 \%$ after four months, $42.0 \%$ after eight months and the lowest decrement $(40.3 \%)$ was recorded after one year storage, regardless the storage packages.

The results also showed that the packaging type was found to be either preserved the menthol percentage of peppermint dried herb, or led to a decrement, this trend was clearly showed throughout the storage period. Accordingly, the highest menthol content was detected in case of carton boxes, while the lowest one found in plastic and Jute cases. Data also reported that, an interaction was found between the three factors that used in this investigation. It was found that, after one year storage period the highest menthol content was determined in peppermint herb with using solar drying method and packaging in carton boxes. 
In general, the ratio of menthol decreased through storage period and the lowest decrement was with shad drying treatment in the carton package; however, the highest decrement was with solar and direct sun dried mint in the plastic and Jute cases.

\section{b-3- Menthone percentage}

For menthone percentage in peppermint essential oil the data in Table 5 indicated that the solar drying method gave the highest percentage of menthone in peppermint oil followed by the shade drying and direct sun drying $(39.3,35.1$ and 34.1, respectively).

Data also cleared that, menthone value of peppermint oil was found to be affected by drying methods. The highest menthone percentage was recorded in case of solar drying method (39.3\%), while the lowest one was found in direct sun drying $(34.1 \%)$. The differences between the values of menthone percentage of the three drying methods were significant.

So it could be reported that, the best drying method was solar drying system in which the evaporation of volatile oil of the peppermint herb was less than the other drying methods. As for the storage period, data also indicated by storage period. It was found that, menthone percentage gradually decreased as the storage period was increased. So, menthone percentage was $(36.17 \%$ average) in zero time (sep.2006) then this value was decreased to $31.1 \%$ after four months, $28.3 \%$ after eight months and the lowest decrement $(25.8 \%)$ was recorded after one year storage, regardless the storage packages.

For the packaging types and its effect on menthone percentage of peppermint dried herb oil, it was showed that, the packaging type was found to be either preserved the menthone percentage of peppermint dried herb, or led to a decrement, this trend was clearly showed throughout the storage period. Accordingly, the highest menthone percentage was detected in case of carton boxes, while the lowest one found in plastic cases. Data also reported that, an interaction was found between the three factors that used in this investigation, it was found that, after one year storage period the highest menthone percentage was determined in peppermint herb with using solar drying method and packaging in carton boxes. These results agree with Al-Kershi (2003).

Generally the results could be concluded that, the ratio of menthone decreased through storage period and the lowest decreasing level was with shad drying treat mint in the plastic package;

However, the highest decreasing in menthone was with solar-dried mint in the carton package. 


\section{b-4- Iso-menthone percentage:}

The data in Table 6 indicated that the solar drying method gave the highest percentage of Iso-menthone in peppermint oil followed by the shade drying and direct sun drying $(9.7,6.5$ and 6.2 , respectively).

Data also cleared that, Iso-menthone value of peppermint oil was found to be affected by drying methods. The highest Iso-menthone content was recorded in case of solar drying method $(9.7 \%)$, while the lowest one was found in direct sun drying (6.2\%). The differences between the values of Iso-menthone content of the three drying methods were significant. So it could be reported that, the best drying method was solar drying system in which the evaporation of volatile oil of the peppermint herb was less than the other drying methods. As for the storage period, data also indicated by storage period. It was found that, Isomenthone content gradually decreased as the storage period was increased. So, Iso-menthone percentage was (7.47\% average) in zero time (sep.2006) then this value was decreased to $6.56 \%$ after four months, $5.36 \%$ after eight months and the lowest decrement $(4.56 \%)$ was recorded after one year storage, regardless the storage packages.

Results also showed that, the packaging type was found to be either preserved the Iso-menthone percentage of peppermint dried herb, or led to a decrement, this trend was clearly showed throughout the storage period. Accordingly, the highest Iso-menthone content was detected in case of carton boxes, while the lowest one found in plastic and Jute cases. Data also reported that, an interaction was found between the three factors that used in this investigation, it was found that, after one year storage period the highest Isomenthone content was determined in peppermint herb with using solar drying method and packaging in carton boxes. These results agree with Al-Kershi (2003).

The changes in the concentrations of the volatile compounds during drying depend on several factors, such as the drying method and the class of plant. Mint belongs to the Lamiaceae family of plants, which are known to store their essential oils on or near the leaf surfaces Moyler (1994). This might account for the loss of volatile compounds in Mentha $s p$ leaves when oven-dried. Similarly, oven-drying of rosemary at $45 \_\mathrm{C}$ resulted in $7.25 \%$ loss in volatile components, while microwave-drying produced losses of $61.5 \%$ in the same plant (Jaganmohan et al, 1998). However, rosemary, dried at ambient temperature, was similar in essential oil yield to the fresh plant (Iba'ñez et al, 1999).

\section{CONCLUSION}

- In case of good production of peppermint to be true to export standard the study reported that the best method of harvesting was with gloves or 
after wash labors hands with dettol and handling the harvested herb in clear plastic boxes.

- The best drying method that gave the lowest microbes count content was solar drying system then packaged the dried herb in carton boxes?

- Also the best treatment which gave the highest volatile oil content , highest menthol, menthone and Iso menthone content was solar drying system then packed the dried herb in carton boxes.

\section{ACKNOWLEDGEMENT}

The authors would like to express their deep thanks to the head quarter to Prof. Dr. Mohamed Samy, Project Coordinator AERI Institutional Linkage Project (Midwest Universities Consortium for International Activities (MUCIA), and USAID - Egypt for their significant support to do this work..

\section{REFERENCES}

Al-Kershi, A. A. G. (2003). Postharvest packaging and temperature controlled storage of peppermint and sweet Basil herbs destined for medicinal and aromatic uses. Ph.D. Thesis, Faculty of Agriculture, Alexandria University, Egypt.

Asekun, O.T., Grierson D.S. and Afolayan A.J. (2007) Effects of drying methods on the quality and quantity of the essential oil of Mentha longifolia L. subsp. Capensis, Food Chemistry, 101:995-998.

British Pharmacopoeia, (1963). The Pharmaceutical Press 17 Bloomsburg, Square. W.C.I. London.

Cantwell, M. and Reid,M. (1986). Post Harvest Handling of Fresh Culinary Herbs. Perishables Handling 60: 2-4 Vegetable Crops Dept. UC Davis.

Charles, D. J; Simon, J. E; Shock, C. C; Feibert, E. B. G; Smith, R. M; Janick, J and Simon, J. E. (1991)Effect of water stress and postharvest handling on artemisinin content in the leaves of Artemisia annual L. New crops. Proceedings of Second National Symposium: New Crops, Exploration, Research and Commercialization, Indianapolis, Indiana, October 6-9, 1991. 1993, 640-643.

El-Kady, A. T.M. (2003). Techno chemical studies on some horticulture crops (Basil and Majoram). Ph.D. Thesis, Faculty of Agriculture Science, Moshtohor, Zagazig University, Benha Branch, Egypt.

Emam, M.S. (1999). Effect of some postharvest treatments on the storage and quality of green onion. Ph.D. Thesis, Faculty of Agriculture, Ain Shams University, Egypt. 
Fatouh, M; Metwally, M. N; Helali, A. B; Shedid, M. H.(2006): Herbs drying using a heat pump dryer. Energy Conversion and Management. 47(15/16): 2629-2643.

Harris, Dadiel C. (2003). Quantitative Chemical Analysis $6^{\text {th }}$ Edition. New York: W.H. Freeman.

Iba'ñ ez, E., Oca, A., de Murga, G., Lo'pez-Sebastia'n, S., Tabera, J. and Reglero, G. (1999). Supercritical fluid extraction and fractionation of different preprocessed rosemary plants. Journal of Agriculture and Food Chemistry, 47: 1400-1404.

Jaganmohan, R. L., Meenakshi, S., Raghavan, B. and Abraham, K. O. (1998). Supercritical fluid extraction and fractionation of different preprocessed rosemary plants. Journal of Food Quality, 21: 107-115.

Karousou, R. A., Lanaras, T. B. and Kokkini, S. (1998). Piperitone oxide rich Essential oils from Mentha longifolia subsp. petiolata and M. x villous- nervata grown wild on the Island of Crete (S Greece). Journal of Essential Oil Research, 10 (4), 375-379.

Manuel Aira, Fernando Monroy and Jorge, A.M. (2008) Dominguez Changes in bacterial numbers and microbial activity of pig slurry during gut transit of epigamic and anemic earthworms Journal of Hazardous Materials, 162: 1404-1407.

Merck, E. (1977). "Microbiology" Dehydrated Culture media Bases Sundry Preparation for Microbiology. Darmstadt, Federal Republic of Germany.

Mimica, D. N., Bozin, B., Sokovic, M., Mihailovic, B and Matavulj, M. (2003). Antimicrobial and antioxidant activities of three Mentha species essential oils. Plant Medica, 69(5): 413-419.

Mohamed S.M.A. (2005). Effect of storage on some medicinal plants in Egypt and Morocco M.Sc. Thesis, Faculty of Agriculture, Cairo University, Egypt,: 88-104.

Moyler, D. A. (1994). Spices Recent Advances. In G. Charalambous (Ed.), Spices, herbs and edible fungi (pp. 1-70). Amsterdam: Elsevier.

Muller, J; Conrad,T.; Thome, B and Muhlbauer, W. (1996): Drying of medicinal plants in a plastics solar drier .Institute fur Agrartechnik in den Tropen und Subtrahend, Universidad

Oyedeji, O. A. and Afolayan, A. J. (2005). Chemical composition and antibacterial activity of essential oil of the African Mentha longifolia. Journal of Ethno Pharmacology.

Ozguven, $M$ and Kirici, S (1999) Research on yield, essential oil, contents and components of mint (Mentha) species in different ecologies. Turkish Journal of Agriculture and Forestry, 23 (5) : 465-472. 
Shalaby, A.S; El-Gamasy, A. M; El-Gengaihi, S. E and Khattab, M. D. (1988) Postharvest studies on herb and oil of Mentha arvensis L. Egyptian Journal of Horticulture, 15 (2): 213-224.

Shibamoto, T. (1987). Retention indices in essential oil analysis. In P. Sandra \& C. Bicchi (Eds.), Capillary gas chromatography in essential oils analysis (259-274).New York: Huethig, A. Verlag. Mentha longifolia (L.) Huds. ssp. schimperi Briq. and Mentha spicata L. Grown in Sudan. Journal of Essential Oil Research, 16 (6): 539-541.

Snedercor, G.W. and Cochran, W.G. (1967): Statistical Methods. Iow State University, Press Amer., Iow. USA.

Stafford, G.I., J“ager, A.K. and van Staden, J.( 2004). Effect of storage on the chemical composition and biological activity of several popular South African medicinal plants. Journal of Ethno Pharmacology (in review).

Tomkins, R. and Chennell, A. (2000). Storing and Handling Culinary Herbs. Institute for Horticultural Development, Victoria. Kura Industries Research of Development Corporation 69.

Zheljazkov, V. D; Jeliazkova, E. A; Craker, L. E; Yankov, B; Georgieva, T; Kolev, T; Kovatcheva, N; Stanev, S; Margina, A; Caffini, N (ed.); Bernath, J (ed.); Craker, L (ed.); Jatisatienr, A. and Giberti, G. (1999) Heavy metal uptake by mint Proceedings of Second World Congress on Medicinal and Aromatic Plants, WOCMAP-2. Biological Resources, Sustainable Use, Conservation and Ethno Botany, Mendoza, Argentina, 10-15 November, 1997. Acta-Horticulture, 500: 111-117. 


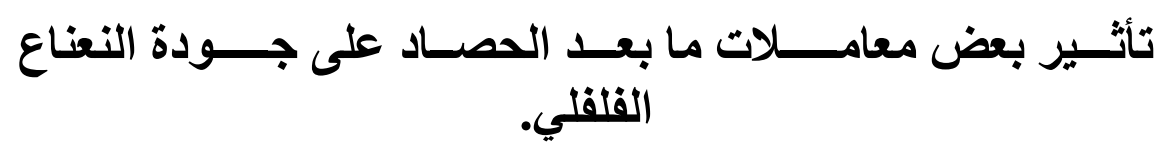

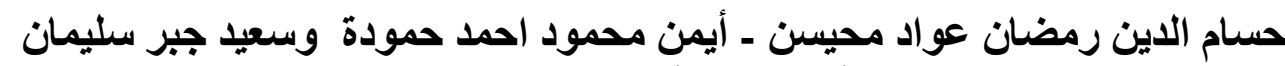

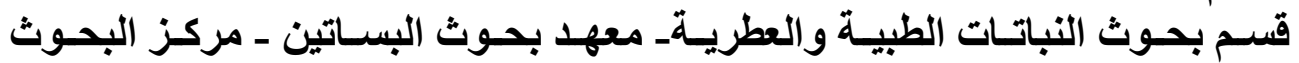

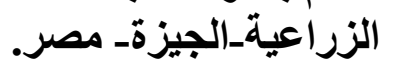

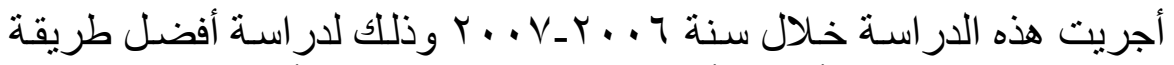

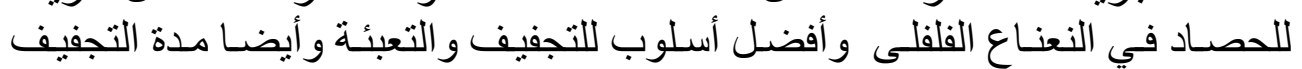

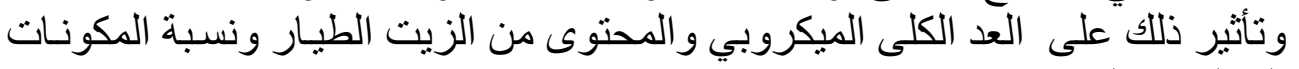

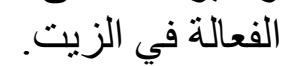

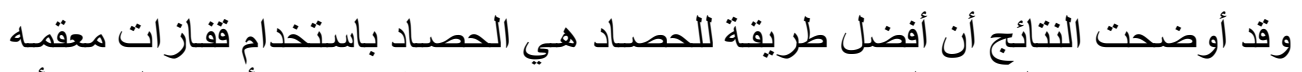

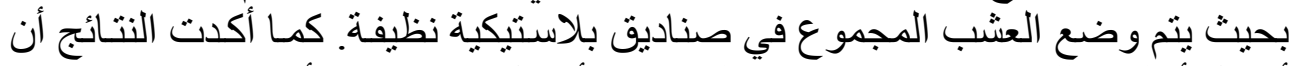

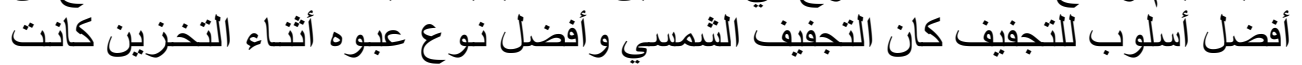

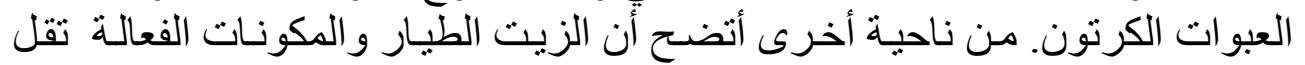

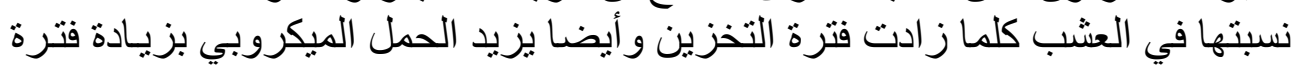

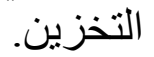

